Review article

\title{
Extracorporeal resuscitation for refractory out-of-hospital cardiac arrest in adults: A systematic review of international practices and outcomes $^{\text {is }}$
}

\author{
Iván Ortega-Deballon ${ }^{\mathrm{a}, \mathrm{b}, \mathrm{c}, \mathrm{d}, \mathrm{e}, *}$, Laura Hornby ${ }^{\mathrm{f}, \mathrm{g}}$, Sam D. Shemie ${ }^{\mathrm{g}, \mathrm{h}, \mathrm{i}}$, Farhan Bhanji ${ }^{\mathrm{h}, \mathrm{i}, \mathrm{j}}$, \\ Elena Guadagno ${ }^{\mathrm{k}}$
}

${ }^{a}$ Canadian National Transplant Research Program, Canada

${ }^{\mathrm{b}}$ Research Institute McGill University Health Centre, Montréal, Canada

c Centre de Prélèvement d'Organes and Laboratoire de Simulation, Hôpital du Sacré-Cœur, Montréal, Canada

${ }^{\mathrm{d}}$ Faculty of Medicine and Health Sciences, Universidad de Alcalá de Henares, Madrid, Spain

e Helicopter Emergency Medical Service (SUMMA 112), Madrid, Spain

f DePPaRT Study, Pediatric Critical Care, Children's Hospital of Eastern Ontario Research Institute, Ottawa, Canada

g Deceased Donation, Canadian Blood Services, Ottawa, Canada

h Division of Critical Care, Montreal Children's Hospital, McGill University Health Centre, Montreal, Canada

${ }^{\mathrm{i}}$ McGill University, Montreal, Canada

${ }^{\mathrm{j}}$ Royal College of Physicians and Surgeons of Canada, Canada

${ }^{\mathrm{k}}$ Medical Library, McConnell Resource Centre, McGill University Health Centre, Montreal, Canada

\section{A R T I C L E I N F O}

\section{Article history:}

Received 4 August 2015

Received in revised form 5 November 2015

Accepted 21 January 2016

\section{Keywords:}

Extracorporeal resuscitation

Out-of-hospital cardiac arrest

Refractory cardiac arrest

Cardiopulmonary resuscitation

Deceased organ donation

Anoxic brain injury

\begin{abstract}
A B S T R A C T
Aim: Extracorporeal resuscitation during cardiopulmonary resuscitation (ECPR) deploys rapid cardiopulmonary bypass to sustain oxygenated circulation until the return of spontaneous circulation (ROSC). The purpose of this systematic review is to address the defining elements and outcomes (quality survival and organ donation) of currently active protocols for ECPR in refractory out-of-hospital cardiac arrest (OHCA) of cardiac origin in adult patients. The results may inform policy and practices for ECPR and help clarify the corrresponding intersection with deceased organ donation.

Methods: We searched Medline, Embase, Cochrane and seven other electronic databases from 2005 to 2015 , with no language restrictions. Internal validity and the quality of the studies reporting outcomes and guidelines were assessed. The review was included in the international prospective register of systematic reviews (Prospero, CRD42014015259).

Results: One guideline and 20 outcome studies were analyzed. Half of the studies were prospective observational studies assessed to be of fair to good methodological quality. The remainder were retrospective cohorts, case series, and case studies. Ages ranged from 16 to 75 years and initial shockable cardiac rhythms, witnessed events, and a reversible primary cause of cardiac arrest were considered favorable prognostic factors. CPR duration and time to hospital cannulation varied considerably. Coronary revascularization, hemodynamic interventions and targeted temperature management neuroprotection were variable. A total of 833 patients receiving this ECPR approach had an overall reported survival rate of
\end{abstract}

Abbreviations: ECPR, extracorporeal resuscitation; ROSC, return of spontaneous circulation; OHCA, out-of-hospital cardiac arrest; CPC, cerebral performance category;

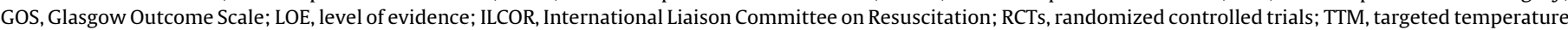

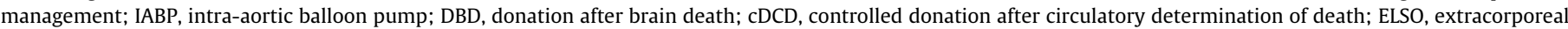
life support organization.

is A Spanish translated version of the abstract of this article appears as Appendix in the final online version at http://dx.doi.org/10.1016/j.resuscitation.2016.01.018.

* Corresponding author at: "ECPR Project: Refractory OHCA \&/or Deceased Organ Donation Option", Facultad de Medicina y Ciencias de la Salud, Departamento de Enfermería, Universidad de Alcalá de Henares, Ctra de Madrid-Barcelona, km 33,600, E-28805 Acalá de Henares, Madrid, Spain.

E-mail addresses: iviortega@gmail.com (I. Ortega-Deballon), lhornby@uottawa.ca (L. Hornby), sam.shemie@mcgill.ca (S.D. Shemie), farhan.bhanji@mcgill.ca (F. Bhanji), elena.guadagno@muhc.mcgill.ca (E. Guadagno). 
$22 \%$, including $13 \%$ with good neurological recovery. Additionally, 88 potential and 17 actual deceased organ donors were identified among the non-survivor population in 8 out of 20 included studies. Study heterogeneity precluded a meta-analysis preventing any meaningful comparison between protocols, interventions and outcomes.

Conclusions: ECPR is feasible for refractory OHCA of cardiac origin in adult patients. It may enable neurologically good survival in selected patients, who practically have no other alternative in order to save their lives with quality of life, and contribute to organ donation in those who die. Large, prospective studies are required to clarify patient selection, modifiable outcome variables, risk-benefit and cost-effectiveness.

(C) 2016 Elsevier Ireland Ltd. All rights reserved.

\section{Introduction}

Sudden cardiac arrest is the main cause of death worldwide in previously healthy people. The global incidence of OHCA in adults is 62 cases per 100,000 persons per year, from which 75 to $85 \%$ have a cardiac origin. ${ }^{1}$ Despite recent improvements in enhancing successful resuscitation in the prehospital setting, overall outcomes remain poor in most venues. ${ }^{1}$ The overall reported survival to hospital discharge is 6\% in North America, ${ }^{1}$ 9\% in Europe, $11 \%$ in Australia and $2 \%$ in Japan. ${ }^{2}$

Extracorporeal resuscitation deploys a modified form of cardiopulmonary bypass, maintaining circulation until an effective cardiac output can be restored. This technique enhances coronary blood flow and preserves the heart's viability, increasing the chance of ROSC. The supply of oxygenated blood flow to the the body and brain prevents organ dysfunction and increases the likelihood of survival with a good neurological recovery. ${ }^{3}$ It is referred to as ECPR for patients in cardiac arrest when conventional resuscitation attempts fail, and it provides oxygenated circulation to extend the time window to diagnose and treat the underlying primary cause of the arrest. In recent years, ECPR has been proposed as an effective therapy not only for in-hospital cardiac arrest, but also for OHCA. ${ }^{4,5}$ However, the results have been mixed due to heterogeneity in study populations, interventions and patient follow-up. In OHCA events, adult patients are known to be younger, previously healthy and the cause of cardiac arrest is more likely of cardiac origin. Therefore, these sudden death episodes are potentially more reversible than in patients who suffer an in-hospital cardiac arrest associated with many comorbidities. Given ROSC is not achieved in the majority of refractory OHCAs ${ }^{1,2}$ the ECPR strategy may be a final option for these selected patients "too healthy to die". 6

The purpose of this systematic review is to address the defining elements and outcomes (quality survival and organ donation) of currently active protocols for ECPR in refractory OHCA of cardiac origin in adult patients. Further understanding of survival outcomes versus risks of anoxic brain injury and death may inform policy and practices for ECPR and the corrresponding intersection with deceased organ donation and transplantation.

\section{Methods}

Design of the study and search strategy

A systematic review of the literature was conducted according to health care reviews from the University of York's Center for Reviews and Dissemination. ${ }^{7}$

Medline (OvidSP), Embase (OvidSP), Cochrane (Wiley) and seven other electronic databases were searched by an expert librarian (EG) from January 1st, 2005 to May 25, 2015 with no language restrictions. Articles identified included variations of the terms ECPR or extracorporeal circulation, found as textwords in the Title/Abstract or MeSH. These were combined with variations of resuscitation, out of hospital, in hospital, cardiac and organ donation terms found in the Title/Abstract or MeSH. We also searched Google Scholar, clinicaltrial.gov, as well as reference lists of included studies, abstracts, unpublished reports, personal libraries (IO-D), professional organization reports and government agency statements on ECPR. Two reviewers (IO-D \& LH) extracted main variables. Internal validity and the quality of the studies reporting outcomes and guidelines were assessed. The review was included in the international prospective register of systematic reviews (Prospero, CRD42014015259) (see Additional file 1 for search strategy details).

We used a modified PICOTS format. Population: adults with refractory OHCA of cardiac origin, who were considered candidates for ECPR; Intervention: ongoing resuscitation during transport, followed by ECPR and other adjuncitve therapies until and/or early after ROSC; Control: although most of the selected studies are single-arm studies, conventional resuscitation was compared to the ECPR strategy in applicable studies; Outcomes: description of practices based on ECPR protocols applied to the population, survival with quality of life according to a cerebral performance category (CPC) score 1-2 or Glasgow Outcome Scale (GOS) score 4-5 at discharge, and potential organ donation; Time: from January 2005 to May 2015; Setting: organizations that produced recommendations or conducted studies consistent with our eligibility criteria.

\section{Eligibility criteria}

Studies reporting results from ECPR in adult patients with refractory OHCA of cardiac origin and recommendations for ECPR endorsed by any professional society or health care authority were included. We excluded editorials, reviews, abstracts, letters or personal opinions. Human studies that included patients with cardiac arrest of non-cardiac origin (e.g. trauma, massive bleeding, hypothermia, poisoning, near drowning, etc.) and animal studies were also excluded. Two trained reviewers (IO-D \& LH) selected the studies and screened citations, retrieved the full texts and independently reviewed them to assess study eligibility. Disagreements were resolved by consensus or after input of two other expert reviewers (SDS \& FB). We used EndNote manager software (EndNote X7.1 version, by Thomson Reuters) to manage the collection of publications. Fig. 1 presents the flow chart study selection process (PRISMA).

\section{Data extraction and quality assessment}

Two reviewers (IO-D and LH) extracted data after creating an Excel (Excel version 2013, by Microsoft Office) data collection tool that was piloted in a sample from included studies. The spreadsheet tabulated the following variables: authors, country, setting, year of protocol, methodology, eligibility criteria, number of cases, interventions, timelines, results (survival with quality of life and potential/actual deceased donors) and conclusions.

The internal validity of the studies was assessed (See Table 1) independently by four reviewers (IO-D, LH, SDS \& FB) and guideline 
Table 1

Characteristics and outcomes of included studies.

\begin{tabular}{|c|c|c|c|c|c|c|c|c|c|c|c|}
\hline $\begin{array}{l}\text { Study country, } \\
\text { region }\end{array}$ & Study design & Time period & $\begin{array}{l}\text { LOE } \\
\text { (quality) }\end{array}$ & Sample size & $\begin{array}{l}\text { Age }^{\mathrm{a}} \\
\text { (years) } \\
\text { male \% }\end{array}$ & $\begin{array}{l}\text { Cardiac rhythm } \\
\text { no. (\%) }\end{array}$ & $\begin{array}{l}\text { No flow }{ }^{\mathrm{b}} \\
\text { period } \\
\text { (min) }\end{array}$ & $\begin{array}{l}\text { Low flow }{ }^{\mathrm{b}} \\
\text { period (min) }\end{array}$ & 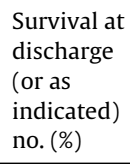 & $\begin{array}{l}\text { Neurological } \\
\text { outcome at } \\
\text { discharge (or as } \\
\text { indicated) no. } \\
\text { (\%) }\end{array}$ & $\begin{array}{l}\text { Organ donor } \\
\text { no. } \\
\text { (potential/actual) }\end{array}$ \\
\hline $\begin{array}{l}\text { Shin et al. } .17 \\
\text { Korea, Seoul }\end{array}$ & Case report & 2006 & 4 (fair) & 1 & $37(100)$ & $1(100) \mathrm{VF}$ & 0 & approx 120 & $1(100)$ & 1 (100) CPC-1 & NA \\
\hline $\begin{array}{r}\text { Nagao et al. }{ }^{15, c} \\
\text { Japan, Tokyo }\end{array}$ & $\begin{array}{l}\text { Prospective } \\
\text { observational }\end{array}$ & $\begin{array}{l}\text { November } \\
2000 \text { December } \\
2007\end{array}$ & 4 (good) & 171 & MR & $\begin{array}{l}143(84) \mathrm{VF} / \mathrm{VT} \\
18(10) \mathrm{PEA} \\
10(6) \mathrm{AS}\end{array}$ & MR & MR & $33(19)$ & 21 (12) CPC-1,2 & NR \\
\hline $\begin{array}{l}\text { Lebreton } \\
\text { et al. } \\
\text { France, Paris }\end{array}$ & Case report & 2010 & 4 (fair) & 1 & $48(100)$ & $1(100)$ AS & $<1$ & $<59$ & $0(0)$ & NA & NR \\
\hline $\begin{array}{l}\text { Le Guen } \\
\text { et al }^{20, c} \\
\text { France, Paris }\end{array}$ & $\begin{array}{l}\text { Prospective } \\
\text { observational }\end{array}$ & $\begin{array}{l}\text { January } 2008 \\
\text { August } 2010\end{array}$ & 4 (good) & 51 & $42(90)$ & $\begin{array}{l}32(63) \mathrm{VF} \\
15(29) \mathrm{AS} \\
4(8) \mathrm{PEA}\end{array}$ & 3 & NR & $\begin{array}{l}2(4) \\
\text { at } 28 \mathrm{~d}\end{array}$ & $\begin{array}{l}2(4) \operatorname{GOS} 4,5 \\
\text { at } 6 \text { months }\end{array}$ & NR \\
\hline $\begin{array}{l}\text { Megarbane } \\
\text { et al. }^{22} \\
\text { France, Paris }\end{array}$ & $\begin{array}{l}\text { Prospective } \\
\text { observational }\end{array}$ & $2005-2008$ & 4 (good) & 47 & MR & $\mathrm{MR}$ & MR & MR & $1(2)$ & 1 (2) CPC-1 & NR \\
\hline $\begin{array}{l}\text { Avalli et al }{ }^{26, c} \\
\text { Italy, Monza }\end{array}$ & $\begin{array}{l}\text { Retrospective } \\
\text { database } \\
\text { review }\end{array}$ & $\begin{array}{l}\text { January } 2006 \\
\text { February } 2011\end{array}$ & 4 (good) & 18 & $46(94)$ & $\begin{array}{l}16 \text { (89) VF/VT } \\
2 \text { (11) AS/PEA }\end{array}$ & 1 & 77 & $\begin{array}{l}1(5) \\
\text { at } 28 \mathrm{~d}\end{array}$ & $\begin{array}{l}1(5) \mathrm{GOS} \geq 4 \\
\text { at } 6 \text { months }\end{array}$ & $10 \mathrm{DBD} / \mathrm{NR}$ \\
\hline $\begin{array}{l}\text { Haneya } \\
\text { et al. }{ }^{24, c} \\
\text { Germany, } \\
\text { Resenburg }\end{array}$ & $\begin{array}{l}\text { Retrospective } \\
\text { database } \\
\text { review }\end{array}$ & $\begin{array}{l}\text { January } 2007 \\
\text { January } 2012\end{array}$ & 4 (good) & 26 & $48(65)$ & $\begin{array}{l}12(46) \mathrm{VF} / \mathrm{VT} \\
2 \text { (8) PEA } 12 \\
\text { (46) AS }\end{array}$ & NR & $70(55-110)$ & $4(15)$ & $\begin{array}{l}\text { NR for OHCA } \\
\text { alone }\end{array}$ & NR \\
\hline $\begin{array}{l}\text { Shinar et al. }{ }^{30} \\
\text { US/San Diego }\end{array}$ & Case report & 2011 & 4 (fair) & 1 & $59(100)$ & $1(100) \mathrm{VF}$ & 0 & 61 & $1(100)$ & 1 (100) CPC-1 & NA \\
\hline $\begin{array}{l}\text { Fagnoul } \\
\text { et al. }{ }^{28, g} \\
\text { Belgium, } \\
\text { Brussels }\end{array}$ & $\begin{array}{l}\text { Prospective } \\
\text { observational }\end{array}$ & $\begin{array}{l}\text { January } 2012 \\
\text { December } \\
2012\end{array}$ & 4 (good) & 7 & MR & MR & MR & MR & $2(29)$ & 2 (29) CPC-1 & $\begin{array}{l}3 \text { DBD, } 1 \text { DCD } / 1 \\
\text { DBD, 1DCD }\end{array}$ \\
\hline $\begin{array}{l}\text { Lamhaut } \\
\text { et al. }^{19} \\
\text { France, Paris }^{\text {Fan }}\end{array}$ & $\begin{array}{l}\text { Pilot } \\
\text { prospective } \\
\text { observational }\end{array}$ & $\begin{array}{l}\text { January } 2011 \\
\text { January } 2012\end{array}$ & 4 (fair) & 7 & $42(86)$ & $5(71) \mathrm{VF} / \mathrm{VT}$ & 4 (mean) & 72 (mean) & $\begin{array}{l}2(28) \\
\text { at } 7 \mathrm{~d}\end{array}$ & $\begin{array}{l}1(14 \%) \text { CPC } 1 \\
\text { at 90d }\end{array}$ & 3 DBD/2 DBD \\
\hline $\begin{array}{l}\text { Leick et al. }{ }^{25} \\
\text { Germany, } \\
\text { Bad Nauheim }\end{array}$ & $\begin{array}{l}\text { Retrospective } \\
\text { chart review }\end{array}$ & $\begin{array}{l}\text { January } 2010 \\
\text { December } \\
2011\end{array}$ & 4 (good) & 28 & MR & MR & MR & MR & $11(39)$ & 8 (29) CPC-1 & NR \\
\hline $\begin{array}{l}\text { Maekawa } \\
\text { et al. }^{13} \\
\text { Japan, } \\
\text { Sapporo }\end{array}$ & $\begin{array}{l}\text { Post hoc } \\
\text { analysis of } \\
\text { prospective } \\
\text { observational }\end{array}$ & $\begin{array}{l}\text { January } 2000 \\
\text { September } \\
2004\end{array}$ & 3 (good) & 53 & $54(83)$ & $31(60) \mathrm{VF} / \mathrm{VT}$ & 2 & 49 & $17(32)$ & $\begin{array}{l}8(15) \\
\text { CPC- } 1,2 \\
\text { at 90 d }\end{array}$ & $44 / 0^{d}$ \\
\hline $\begin{array}{l}\text { Mojoli et al. }{ }^{27} \\
\text { Italy, Pavia }\end{array}$ & $\begin{array}{l}\text { Prospective } \\
\text { observational }\end{array}$ & $\begin{array}{l}\text { January } 2008 \\
\text { June } 2011\end{array}$ & 4 (fair) & 7 & 55 & NR & 7 & $\begin{array}{l}93 \text { (no flow } \\
\text { included) }\end{array}$ & $0(0)$ & NA & $\begin{array}{l}3 \mathrm{DBD}, 1 \mathrm{DCD} / 2 \\
\mathrm{DBD}, 1 \mathrm{DCD}\end{array}$ \\
\hline $\begin{array}{l}\text { Tazarourte } \\
\text { et al. }{ }^{23, \mathrm{f}} \\
\text { France, Ile de } \\
\text { France region }\end{array}$ & $\begin{array}{l}\text { Retrospective } \\
\text { observational }\end{array}$ & 2008-2010 & 4 (good) & 27 & $39(56)$ & $\begin{array}{l}\text { VF } 7(26) \\
\text { PEA } 6(22) \\
\text { AS } 14(52)\end{array}$ & 2 & $\begin{array}{l}140 \text { (no flow } \\
\text { included) }\end{array}$ & $1(4)$ & 1 (4) CPC-1 & 10 DBD/10 DBD \\
\hline $\begin{array}{l}\text { Kim et al. }{ }^{12, c} \\
\text { Korea, Seoul }\end{array}$ & $\begin{array}{l}\text { Post hoc } \\
\text { analysis of } \\
\text { prospective } \\
\text { observational }\end{array}$ & $\begin{array}{l}\text { May } 2006 \\
\text { December } \\
2013\end{array}$ & 3 (good) & 55 & $53(75)$ & $\begin{array}{l}31(56) \mathrm{VF} / \mathrm{VT} \\
14(26) \mathrm{AS} \\
10(18) \mathrm{PEA}\end{array}$ & 7 & 62 & $9(16)$ & $\begin{array}{l}8 \text { (15) CPC- } 1,2 \\
1 \text { (2) CPC-4 }\end{array}$ & NR \\
\hline
\end{tabular}




\begin{tabular}{|c|c|c|c|c|c|c|c|c|c|c|c|}
\hline $\begin{array}{l}\text { Study country, } \\
\text { region }\end{array}$ & Study design & Time period & $\begin{array}{l}\text { LOE } \\
\text { (quality) }\end{array}$ & Sample size & $\begin{array}{l}\text { Age }^{\mathrm{a}} \\
\text { (years) } \\
\text { male \% }\end{array}$ & $\begin{array}{l}\text { Cardiac rhythm } \\
\text { no. (\%) }\end{array}$ & $\begin{array}{l}\text { No flow }{ }^{\mathrm{b}} \\
\text { period } \\
\text { (min) }\end{array}$ & $\begin{array}{l}\text { Low flow }{ }^{\mathrm{b}} \\
\text { period (min) }\end{array}$ & $\begin{array}{l}\text { Survival at } \\
\text { discharge } \\
\text { (or as } \\
\text { indicated) } \\
\text { no. (\%) }\end{array}$ & $\begin{array}{l}\text { Neurological } \\
\text { outcome at } \\
\text { discharge (or as } \\
\text { indicated) no. } \\
(\%)\end{array}$ & $\begin{array}{l}\text { Organ donor } \\
\text { no. } \\
\text { (potential/actual) }\end{array}$ \\
\hline $\begin{array}{l}\text { Mochizuki } \\
\text { et al. }{ }^{14} \\
\text { Japan, } \\
\text { Matsumoto }\end{array}$ & $\begin{array}{l}\text { Retrospective } \\
\text { database } \\
\text { review }\end{array}$ & $\begin{array}{l}\text { April } 2004 \\
\text { March } 2013\end{array}$ & 4 (good) & 32 & $51(78)$ & MR & MR & MR & $\begin{array}{l}8(25) \\
\text { at 30d }\end{array}$ & $\begin{array}{l}5(16) \\
\text { CPC- } 1,2 \\
\text { at } \mathbf{3 0 d}\end{array}$ & 5 DBD, $5 \mathrm{DCD} / 0$ \\
\hline $\begin{array}{l}\text { Putzer et al. }{ }^{29} \\
\text { Austria, } \\
\text { Innsbruck }\end{array}$ & Case study & NR & 4 (fair) & 1 & $43(100)$ & $1(100) \mathrm{VF}$ & $<5$ & 107 & $1(100)$ & 1 CPC-1 & NA \\
\hline $\begin{array}{l}\text { Sakamoto } \\
\text { et al. }{ }^{16} \\
\text { Japan, } \\
\text { Yokohama } \\
\text { City }\end{array}$ & $\begin{array}{l}\text { Prospective } \\
\text { observational }\end{array}$ & $\begin{array}{l}\text { September } \\
2008 \\
\text { September } \\
2011\end{array}$ & 2 (good) & 260 & $56.3(90)$ & NR & NR & NR & $\begin{array}{l}69(27) \\
\text { at 30d }\end{array}$ & $\begin{array}{l}32(12) \\
\mathrm{CPC}-1,2 \\
37(14) \mathrm{CPC}-3,4 \\
\text { at 30 d }\end{array}$ & NR \\
\hline $\begin{array}{l}\text { Stub et al. }{ }^{31} \\
\text { Australia, } \\
\text { Melbourne }\end{array}$ & $\begin{array}{l}\text { Prospective } \\
\text { observational }\end{array}$ & $\begin{array}{l}\text { “32 month } \\
\text { period” }\end{array}$ & 4 (fair) & 9 & MR & MR & MR & MR & $5(56)$ & 3 (33)СРC-1 & $\begin{array}{l}3 / 0 \text { (type not } \\
\text { specified) }\end{array}$ \\
\hline $\begin{array}{l}\text { Wang et al. }{ }^{18} \\
\text { Taiwan,Taipei }\end{array}$ & $\begin{array}{l}\text { Prospective } \\
\text { observational }\end{array}$ & $\begin{array}{l}\text { January } 2007 \\
\text { September } \\
2012\end{array}$ & 4 (good) & 31 & $50.7(75)$ & $\begin{array}{l}15 \text { (48) VF/VT } \\
16 \text { (52) AS/PEA }\end{array}$ & NR & $\begin{array}{l}67.5 \text { (no flow } \\
\text { included) }\end{array}$ & $12(39)$ & 8 (26) CPC-1,2 & NR \\
\hline Totals & & & & 833 & & & & & $180(22)$ & $\begin{array}{l}104(13)^{\mathrm{e}} \text { good } \\
\text { neurologic } \\
\text { recovery }\end{array}$ & $\begin{array}{l}34 \text { DBD, } 7 \text { DCD } \\
\text { and } 47 \text { not } \\
\text { specified/15 } \\
\text { DBD, } 2 \text { DCD }\end{array}$ \\
\hline
\end{tabular}

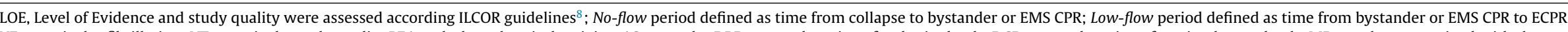

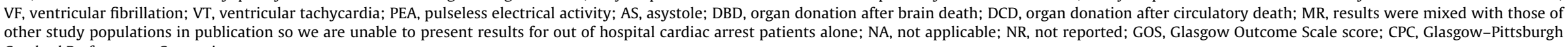
Cerebral Performance Categories.

a Unless otherwise indicated, values presented are means for cohort studies and individual values for case studies.

b Unless otherwise indicated, values presented are medians for cohort studies and individual values for case studies.

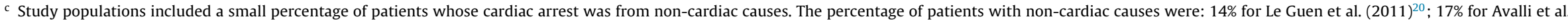
$(2012)^{26} ; 39 \%$ for Haneya et al. (2012), ${ }^{24}$ NB: in this study pulmonary embolism was considered a non-cardiac cause; and $11 \%$ for Kim et al. $(2014){ }^{12}$

d This percentage $(13 \%, 104 / 807)$ does not include study by Haneya et al. $(2012)^{24}$ as it did not report CPC score in OHCA alone.

e 44 subjects were poor function status patients. There were no organ donors since CDCD is not permitted and DBD cannot be certified under ECMO by law in Japan.

f This study has a total sample size is 27 but only 14 underwent ECPR; the rest were immediately considered as potential donors.

$\mathrm{g}$ Additional data not presented in publication was provided by author in the form of a personal communication. 


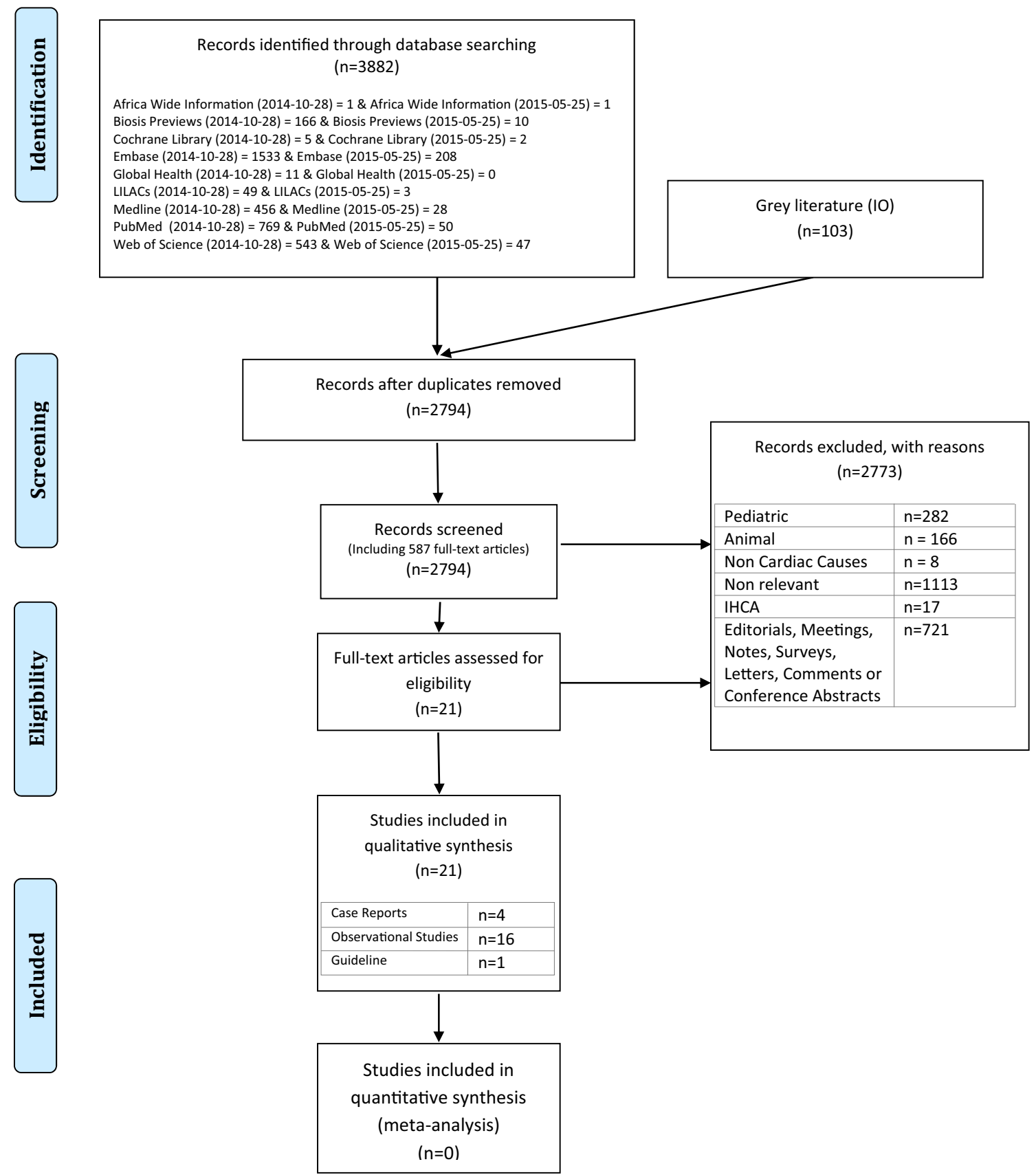

Fig. 1. PRISMA flow chart study selection.

quality (see Additional file 2) by three reviewers (IO-D, LH, FB). For the assessment of studies reporting outcomes we used the level of evidence (LOE) scale tool previously used by the International Liaison Committee on Resuscitation (ILCOR). ${ }^{8}$ The guideline assessment was performed with the Appraisal of Guidelines for Research \& Evaluation (AGREE) instrument, version II. ${ }^{9}$

\section{Data synthesis}

We anticipated clinical heterogeneity in selected studies due to the variability in eligibility criteria of study populations and ECPR procedures. Statistical heterogeneity was identified in relation to disparities in sample size, interventions and timelines along the OHCA process and in post-resuscitation care, as well as in the benefit/harm risk analysis. This heterogeneity also existed in the criteria for defining a good neurological recovery in survivors and for defining potential deceased donors among non-survivors. Therefore, comparison of data was not feasible, precluding any meta-analysis. Rather, we did a tabulation of characteristics of studies (See Table 1). To reduce the heterogeneity we focused our analysis on a subgroup of patients suffering OHCA of cardiac origin. We contacted the authors of all the included studies for further details from their databases.

\section{Results}

A cumulative of 3882 potentially relevant citations were obtained, in addition to 103 from gray literature and 466 from citation tracking, resulting in a total of 2794 references for further review after duplicates were removed. Of these, 2773 were excluded in a first screening for the reasons specified (Fig. 1). Therefore, a final total of 21 references, 20 studies and 1 guideline, were 
I. Timelines and sequence of events and interventions

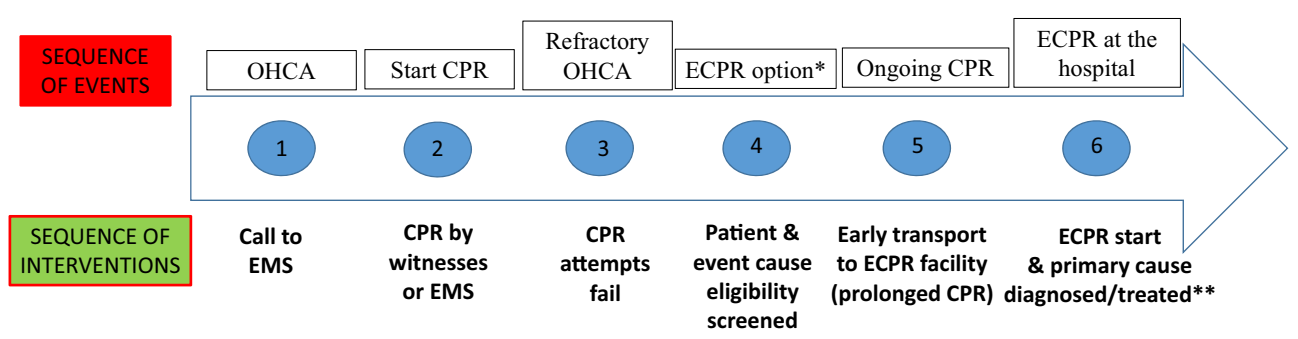

* Patient mustfulfill eligibility criteria \& cardiac cause must be presumed/diagnosed. Then, ECPR team is early prealerted. ** ECPR strategy includes a bundle treatment after ECPR starts (i.e.: ECo, PCI, CAGB, Thrombolysis, TTM, IABP). If ECPR fails or patientis notfinally eligible for this intervention, will receive standard treatments and care according to protocols.

II. Potential outputs of the strategy: different outcomes

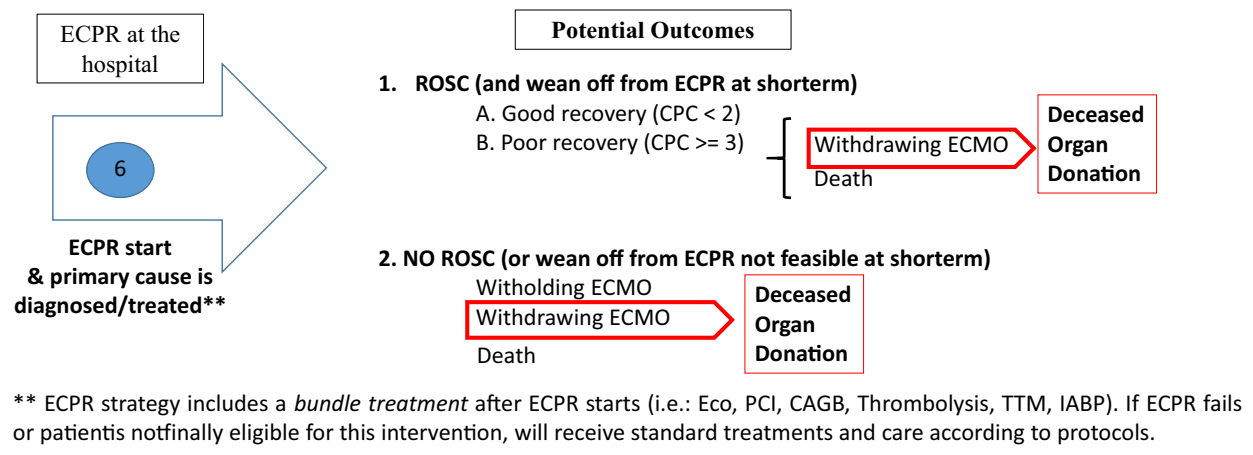

Fig. 2. ECPR strategy - timelines, int and outcomes.

included in our analysis. Fig. 2 depicts timelines, events, interventions and potential outcomes during the ECPR process. Various clinical endpoints may include: ROSC with good neurological recovery (CPC 1-2); ROSC with poor neurological outcome (CPC $\geq 3$ ) leading to poor quality survival or death and/or organ donation; no ROSC and withdrawal of ECMO leading to death and/or organ donation.

\section{ECPR studies}

Twenty studies reporting outcomes were reviewed and are summarized in Table 1. There were no published randomized controlled trials (RCTs) although two (NCT01511666 and NCT01605409) are currently enrolling patients in Prague and Vienna. ${ }^{10,11}$ Four of the selected studies were conducted in Japan, 2 in Korea and 1 in Taiwan, ${ }^{12-18} 5$ in France, ${ }^{19-23} 2$ in Germany ${ }^{24,25}$ and 2 in Italy. ${ }^{26,27}$ The remaining case series and reports were from Belgium, ${ }^{28}$ Austria, ${ }^{29}$ USA $^{30}$ and Australia. ${ }^{31}$

The large majority of included studies were case reports, case series, and retrospective cohort studies, all of them LOE of 4 . Maekawa et al. ${ }^{13}$ and Kim et al. ${ }^{12}$ performed a post hoc analysis of a prospective observational study, LOE 3. Sakamoto et al. ${ }^{16}$ completed a large prospective observational study (LOE 2) which is the strongest level of evidence identified. Most of the included studies presented high risk of confounding bias and threats to external validity because of their observational design. However, the methodological quality assessment of the 20 included studies resulted in a rating of good for 14 studies $^{12-16,18,20,22-28}$ and fair for the other $6^{17,19,21,29-31}$ (see Table 1 ).

\section{Guideline appraisal}

This review identified only one guideline on the specific management of refractory cardiac arrest with ECPR. It was developed by a group of experts and endorsed by different professional societies and resuscitation boards from France. Considerations include a potentially reversible cardiac arrest cause (e.g. hypothermia or intoxication), limitations to the duration of no-flow and low-flow periods, the presence of signs of life during resuscitation as well as the level of end tidal carbon dioxide detected during the resuscitation attempts. In order to assess the rigor of clinical practice guideline development, we used the AGREE II tool. In the Additional file 2 we include the scores for each of 6 different domains. The objectives and targeted users were well described and identified. Although recommendations were presented with clarity, the domains related to the "Stakeholder Involvement", the "Rigor of Development" and "Editorial Independence" obtained low scores. The authors acknowledged the low LOE 5 for their recommendations. Despite methodological limitations, the strength of the guideline is clarity of eligibility criteria and it provides a useful and simple decision tool for physicians and nurses in the field.

\section{Patient characteristics}

In most studies, age of patients ranged from 16 to 75 years. The no-flow time periods were generally less than 5 min (range from 0 to 7 ) and the low-flow time periods were variable (range from 49 to 140, with no-flow period included in some studies). Factors identified as favorable prognosis included witnessed events, initial shockable cardiac rhythms and the identification of a potentially reversible cause of cardiac arrest. The duration of time defining failed conventional resuscitation and refractory cardiac arrest varied between studies, ranging from 10 to $30 \mathrm{~min}$ prior to initiating the ECPR process. The main exclusion criteria were the pre-existence of severe comorbidities, neurological disabilities, a valid do not attempt resuscitation order and the identification of a primary non-cardiac etiology (Table 2 ). 
Table 2

Commonly cited ECPR inclusion and exclusion criteria and bundle treatments performed.

Inclusion criteria

- Age cutoffs, usually <75 years (low end: 10 years; high end: no upper age)

- Rhythm at the time of CPR (when included, specified as favorable to

ventricular arrhythmias or "shockable" rhythms)

- Time interval from collapse to initiation of resuscitation (no flow), generally

$\leq 5$ mins (up to $<15$ mins)

- Witnessed cardiac arrest

- Etiology of arrest, to be of "presumed", "assumed", or "suspected" cardiac etiology

- No ROSC despite optimal CPR, usually by 30 mins (as low as 10 mins) refractory cardiac arrest definition

Exclusion criteria

- Do not resuscitate order

- Severe activities-of-daily-living disability

- Non-cardiac causes of arrest such as severe trauma, uncontrollable bleeding

irreversible brain damage, drug overdose, poisoning, submersion, etc.

- Severe comorbidities (e.g. Often specify as those that would preclude

admission to ICU, i.e. terminal illnesses, malignancies, etc.)

- Hypothermia

Bundle treatment options used during ECPR

- Catheter Lab (e.g. PCI, CABG, etc.) ONLY: 2 studies ${ }^{23,30}$

- Catheter Lab + TTM: 8 studies ${ }^{12,21,22,24,25,28,29,31}$

- Catheter Lab + IABP: 1 study ${ }^{17}$

- Catheter Lab + IABP + TTM: 9 studies $^{13-16,18-20,26,27}$

CPR, cardiopulmonary resuscitation; $\mathrm{PCI}$, percutaneous coronary intervention; CABG, coronary artery bypass grafting; TTM, targeted temperature management, also known as therapeutic mild hypothermia; IABP, intra-aortic balloon pump.

\section{ECPR process}

In all studies ECPR was deployed upon arrival to the hospital with a pre-alerted ECPR team on standby, except in Paris where ECPR is usually performed in the field. ${ }^{19,21}$ Followed by a variable door-to-cannulation period of time, the bundle treatment approach included coronary revascularization in the catheterization lab, and in some studies adjunctive therapies were also deployed (Table 2). These co-interventions were targeted temperature management (TTM) for neurological protection and/or the use of an intra-aortic balloon pump (IABP).

\section{Outcomes}

This systematic review identified a cumulative total of 833 patients in 20 studies. While there was some variability in time points of reported outcomes, the overall reported survival rate was $22 \%$, including $13 \%$ having a good neurological recovery (CPC $1-2$ or GOS 4-5, see Table 1 ). In addition to these short-term results, three studies ${ }^{12,13,19}$ reported patient outcomes at 3 months with an overall survival rate of $21 \%(24 / 115)$, including $15 \%$ (17/115) having good neurological function and five studies ${ }^{16,20,22,26,30}$ reported patient outcomes at 6 months with an overall survival rate of $16 \%$ (61/377), including 9\% (34/377) having good neurological function.

Three studies $^{19,23,26}$ reported on potential organ donors from the group of non-survivors with anoxic brain injury, including donation after brain death (DBD) and controlled donation after circulatory determination of death (cDCD). After contacting all authors, data on organ donation outcomes were provided from 5 additional studies ${ }^{13,14,27,28,31}$ (Table 1 ). A total of 88 potential deceased donors among non-survivors from 8 out of the 20 included studies were identified. Of these potential donors, 17 (19\%) became actual donors: 15 DBD and 2 cDCD. Most donors were identified after inability of ECPR to achieve neurological recovery. However one study managed 13/27 patients as potential donors in the prehospital phase of care based on the duration of no-flow period of the cardiac arrest event. ${ }^{23}$

\section{Discussion}

To our knowledge, this is the first systematic review that summarizes the defining elements and outcomes of ECPR studies in refractory OHCA of cardiac origin in adult patients. Potential outcomes of this strategy include survival with good neurological recovery, survival with poor neurological recovery, or anoxic brain injury resulting in death with or without organ donation. In order to inform practice, we have created an illustrated timeline of the ECPR process and depicted the potential scenarios and outcomes (Fig. 2).

Cumulatively, we report 833 OHCA patients in 20 studies, with an overall survival rate of $22 \%$, including $13 \%$ with good neurological recovery. For those studies reporting longer-term outcomes, overall survival rates were $21 \%$, including $15 \%$ good neurological function at 3 months and $16 \%$ including $9 \%$ good neurological function at 6 months. Eight of twenty studies outlined 88 potential organ donors, $19 \%$ of which became actual organ donors. The vast majority of previously reported outcomes are related to in-hospital cardiac arrest and do not report neurological or organ donation outcomes. Although this review focuses on refractory OHCA of cardiac origin, the results are comparable to previous adult ECPR reports that include various mixes of in/out of hospital cardiac arrest and cardiogenic shock. ${ }^{32}$ Previously reported survival rates to hospital discharge range from 29 to 47\%, including the large Extracorporeal Life Support Organization (ELSO) registry report of 4200 ECPR patients. 6,33,34

Given that this review is based largely on existing case reports, case series or small observational studies, heterogeneity was evidenced in both populations and interventions. There is variability in patient selection, age limits, duration of no-flow, the moment when the OHCA is considered refractory to conventional resuscitation, logistics and clinical pathways, time from cardiac arrest to cannulation, interventions deployed, and levels of care provided before and after ROSC. The decision to offer ECPR was often made on a case-by-case basis at the discretion of the resuscitation team leader, ${ }^{12,14,18,35}$ which may lead to reporting bias. ${ }^{36}$ Randomized controlled trials in OHCA are registered (NCT01511666 and NCT01605409), and currently enrolling patients. ${ }^{10,11}$

What remains unresolved are the optimal patient characteristics, variables associated with good neurological outcomes and the cost-benefit analysis of this complex and resource intensive intervention, ${ }^{3,37}$ The main variables determining neurological outcome ${ }^{38,39}$ presumably are: the duration without cardiac output until resuscitation begins (no-flow period), quality of CPR, and the duration with low cardiac output during resuscitation attempts (low-flow period). ILCOR reviews ${ }^{40,41}$ suggest that the presence of witnesses, shorter duration of resuscitation prior to ECPR, a shockable initial rhythm, and the early identification/treatment of the reversible cause of arrest were factors positively associated with survival to discharge. Although the ILCOR does not recommend the ECPR strategy routinely, it states that in settings where it can be rapidly implemented, ECPR may be considered for select cardiac arrest patients for whom the suspected etiology of the cardiac arrest is potentially reversible during a limited period of mechanical cardiorespiratory support (Class IIb, LOE C-LD). ${ }^{42}$

Innovative strategies seeking to minimize the no-to-low flow period include cannulation in the field followed by rapid deployment of mobile ECPR. ${ }^{19,21}$ The effectiveness should be compared to early transport under high-quality ongoing resuscitation and ECPR institution after arrival to the hospital. Novel therapies are in evolution ${ }^{43,44}$ to enhance cardiac and neurological recovery (Table 2), including percutaneous coronary intervention, intraaortic balloon pump, thrombolysis and targeted temperature management. When offered during or early after resuscitation attempts, results were encouraging. ${ }^{13,16,31,45-47}$ 
In addition to survival outcomes, this review suggests that organ donation after death, while poorly reported, should be included as a relevant outcome in ECPR studies. It is likely that the number of potential donors with irreversible anoxic brain injury may be underestimated as some jurisdictions do not offer donation option under these circumstances. For example, through personal correspondence, Maekawa ${ }^{13}$ reported 44 patients with a poor neurological outcome following ECPR, but explained that at the time of the study, controlled DCD was not performed in Japan, and DBD could only be certified in hemodynamically stable patients which exclude ECPR.

Any innovative resuscitation intervention that improves patient outcome has direct benefits to the patient, and may have an indirect societal benefit arising from patients who will inevitably die but can become organ donors. However, these positive consequences must also be balanced by the potential for undesirable outcomes. Some authors have reported higher survival with good neurological recovery compared to conventional resuscitation, but also higher rates of coma and permanent vegetative state. ${ }^{12,16}$ Thus, it has been stated that the ECPR strategy can lead to the so-called bridge to nowhere in which a patient, not likely to recover, not going to die, is dependent on ongoing life support, ${ }^{36}$ posing burdens to patient, family and the health care system. However, this review demonstrates that survival with poor neurological outcome overall was $9 \%$ and for those studies reporting outcomes at 3 and 6 months it was $6 \%$ and $7 \%$, respectively.

This systematic review has several limitations. Study heterogeneity precluded a meta-analysis preventing any meaningful comparison between protocols, interventions and outcomes. The lack of standardization of definitions at each step of the process and the lack of homogeneity of good outcomes and follow-up times for survivors hindered a more consistent and clear presentation of results. Finally, we were unable to perform any guideline comparisons; only one guideline was identified. Despite these limitations, ECPR is feasible for refractory OHCA of cardiac origin in adult patients. ECPR may increase the neurologically good survival in selected patients. Prospective studies are required to clarify patient selection and modifiable outcome variables. Further investigation is needed to determine whether ECPR cannulation is more effective when performed in pre-hospital or in-hospital settings. A cost-effectiveness analysis of the ECPR strategy is required to inform policy. The deceased organ donation option may be considered a secondary outcome when patient survival with quality of life is not achieved.

\section{Conclusions}

This systematic review describes and compares the international variability in practices, protocols and outcomes for the ECPR strategy in adult patients who suffered a refractory OHCA, informing future protocol development and health policy. The review highlights the need for standardization of definitions and of study outcomes to improve study homogeneity and clarity of findings. We advocate, aligned with ILCOR recommendations, ${ }^{48}$ that future studies report the following outcomes: survival and neurological status (CPC score) at $24 \mathrm{~h}, 1$ month, 3 months, 6 months and 1 year as well as outcomes pertaining to organ donation potential in nonsurvivors such as the mechanism (neurologic versus circulatory) of death and the number of actual donors.

The ECPR strategy is a viable last option for increasing the probability of survival in a potentially hopeless scenario. A bundle of novel therapies are feasible to treat preselected adult patients suffering from a refractory OHCA of cardiac origin. The process includes ECPR and other co-interventions such as percutaneous coronary intervention, intra-aortic balloon pump, thrombolysis and targeted temperature management. When deployed during and/or soon after resuscitation attempts, despite variations in practice and heterogeneity of outcomes, these interventions yield a good neurological survival in $12 \%$ of adults suffering a refractory OHCA. Importantly, prior to ECPR strategy implementation, these patients would not have had practically any chance for survival. Moreover, this strategy has the potential to increase the pool of solid organs available for transplant from non-survivors. This secondary outcome should not be disregarded, from a costeffectiveness point of view, in a global context of organ shortage; it may be a more comprehensive approach to the end-of-life scenario drawn by sudden cardiac arrest events, a major public health burden worldwide.

\section{Author's contributions}

IO-D and LH carried out the systematic review, conceived of the protocol and drafted the manuscript. SDS and FB supervised and participated in the review of study selection and in the quality assessment process. EG carried out the search strategy and led the management of references, designing the figures related to this part. All authors critically reviewed and approved the final manuscript.

\section{Conflict of interest statement}

LH is a paid research consultant for Canadian Blood Services. The other authors declare that they have no competing interests.

\section{Acknowledgements}

We thank Ingrid Soto, Jan Belohlavek, David Rodríguez-Arias and Alfredo Serrano for their support, suggestions and comments during the conception and revision of this manuscript.

IO-D was financially supported by a $\mathrm{PhD}$ research grant from Fundación 'La Caixa', Barcelona, Spain. This Systematic Review is part of his PhD project. He also received the Phyllis and Albert Sussman Accommodation Subsidy for a stay at The Hastings Center, Garrison, New York, USA, while he participated in the writing of this systematic review. IO-D declares that this systematic review would have never been possible without the personal support of Maria and Miguel Ortega.

\section{Appendix A. Supplementary data}

Supplementary data associated with this article can be found, in the online version, at http://dx.doi.org/10.1016/j.resuscitation. 2016.01.018.

\section{References}

1. Goldberg SA, Metzger JC, Pepe PE. Year in review 2011: critical care - out-ofhospital cardiac arrest and trauma. Crit Care 2012:16:247.

2. Berdowski J, Berg RA, Tijssen JG, Koster RW. Global incidences of out-of-hospital cardiac arrest and survival rates: systematic review of 67 prospective studies. Resuscitation 2010:81:1479-87.

3. Chen YS, Lin JW, Yu HY, et al. Cardiopulmonary resuscitation with assisted extracorporeal life-support versus conventional cardiopulmonary resuscitation in adults with in-hospital cardiac arrest: an observational study and propensity analysis. Lancet 2008:372:554-61.

4. Kagawa E, Dote K, Kato M, et al. Should we emergently revascularize occluded coronaries for cardiac arrest? Rapid-response extracorporeal membrane oxygenation and intra-arrest percutaneous coronary intervention. Circulation 2012;126:1605-13.

5. Lazzeri C, Bernardo P, Sori A, et al. Venous-arterial extracorporeal membrane oxygenation for refractory cardiac arrest: a clinical challenge. Eur Heart J Acute Cardiovasc Care 2013;2:118-26.

6. Gaieski DF, Boller M, Becker LB. Emergency cardiopulmonary bypass: a promising rescue strategy for refractory cardiac arrest. Crit Care Clin 2012;28:211-29. 
7. Centre for Reviews and Dissemination. Systematic reviews: CRD's guidance for undertaking systematic reviews in health care. York, United Kingdom: York Publishing Services Ltd., York University; 2009.

8. Morley PT. Evidence evaluation worksheets: the systematic reviews for the evidence evaluation process for the 2010 International Consensus on Resuscitation Science. Resuscitation 2009;80:719-21.

9. Brouwers MC, Kho ME, Browman GP, et al. AGREE II: advancing guideline development, reporting and evaluation in health care. CMAJ: Can Med Assoc J [Journal de l'Association Medicale Canadienne] 2010;182:E839-42.

10. Belohlavek J. Hyperinvasive approach in cardiac arrest. Czech Republic: Charles University; 2012.

11. Schober A. Emergency cardiopulmonary bypass for cardiac arrest. Medical University of Vienna; 2012.

12. Kim S, Jung J, Park J, Park J, Hong Y, Lee S. An optimal transition time to extracorporeal cardiopulmonary resuscitation for predicting good neurological outcome in patients with out-of-hospital cardiac arrest: a propensity-matched study. Crit Care 2014; $18: 535$

13. Maekawa K, Tanno K, Hase M, Mori K, Asai Y. Extracorporeal cardiopulmonary resuscitation for patients with out-of-hospital cardiac arrest of cardiac origin: a propensity-matched study and predictor analysis. Crit Care Med 2013;41:1186-96.

14. Mochizuki K, Imamura H, Iwashita T, Okamoto K. Neurological outcomes after extracorporeal cardiopulmonary resuscitation in patients with out-of-hospital cardiac arrest: a retrospective observational study in a rural tertiary care center. J Intensive Care 2014;2:33.

15. Nagao K, Kikushima K, Watanabe K, et al. Early induction of hypothermia during cardiac arrest improves neurological outcomes in patients with out-of-hospital cardiac arrest who undergo emergency cardiopulmonary bypass and percutaneous coronary intervention. Circ J 2010;74:77-85.

16. Sakamoto T, Morimura N, Nagao K, et al. Extracorporeal cardiopulmonary resuscitation versus conventional cardiopulmonary resuscitation in adults with out-of-hospital cardiac arrest: a prospective observational study. Resuscitation 2014;85:762-8

17. Shin JS, Lee SW, Han GS, Jo WM, Choi SH, Hong YS. Successful extracorporeal life support in cardiac arrest with recurrent ventricular fibrillation unresponsive to standard cardiopulmonary resuscitation. Resuscitation 2007;73:309-13.

18. Wang $\mathrm{CH}$, Chou NK, Becker LB, et al. Improved outcome of extracorporeal cardiopulmonary resuscitation for out-of-hospital cardiac arrest - a comparison with that for extracorporeal rescue for in-hospital cardiac arrest. Resuscitation 2014;85:1219-24.

19. Lamhaut L, Jouffroy R, Soldan M, et al. Safety and feasibility of prehospital extra corporeal life support implementation by non-surgeons for out-of-hospital refractory cardiac arrest. Resuscitation 2013;84:1525-9.

20. Le Guen M, Nicolas-Robin A, Carreira S, et al. Extracorporeal life support following out-of-hospital refractory cardiac arrest. Crit Care 2011:15.

21. Lebreton G, Pozzi M, Luyt CE, et al. Out-of-hospital extra-corporeal life support implantation during refractory cardiac arrest in a half-marathon runner. Resuscitation 2011;82:1239-42.

22. Megarbane B, Deye N, Aout M, et al. Usefulness of routine laboratory parameters in the decision to treat refractory cardiac arrest with extracorporeal life support. Resuscitation 2011;82:1154-61.

23. Tazarourte K, Sapir D, Laborne FX, et al. Refractory cardiac arrest in a rural area: mechanical chest compression during helicopter transport. Acta Anaesthesiol Scand 2013;57:71-6.

24. Haneya A, Philipp A, Diez C, et al. A 5-year experience with cardiopulmonary resuscitation using extracorporeal life support in non-postcardiotomy patients with cardiac arrest. Resuscitation 2012;83:1331-7.

25. Leick J, Liebetrau C, Szardien S, et al. Door-to-implantation time of extracorporeal life support systems predicts mortality in patients with out-of-hospital cardiac arrest. Clin Res Cardiol.: Off J German Cardiac Soc 2013;102: 661-9.

26. Avalli L, Maggioni E, Formica F, et al. Favourable survival of in-hospital compared to out-of-hospital refractory cardiac arrest patients treated with extracorporeal membrane oxygenation: an Italian tertiary care centre experience. Resuscitation 2012;83:579-83.

27. Mojoli F, Venti A, Pellegrini C, et al. Hospital survival and long term quality of life after emergency institution of venoarterial ECMO for refractory circulatory collapse. Minerva Anestesiol 2013;79:1147-55.
28. Fagnoul D, Taccone FS, Belhaj A, et al. Extracorporeal life support associated with hypothermia and normoxemia in refractory cardiac arrest. Resuscitation 2013;84:1519-24.

29. Putzer G, Mair B, Hangler H, Strohle M, Mair P. Emergency extracorporea life support after prolonged out-of-hospital cardiac arrest. J Cardiothorac Vasc Anesth 2014;28:1036-8.

30. Shinar Z, Bellezzo J, Paradis N, et al. Emergency department initiation of cardiopulmonary bypass: a case report and review of the literature. J Emerg Med 2012;43:83-6.

31. Stub D, Bernard S, Pellegrino V, et al. Refractory cardiac arrest treated with mechanical CPR, hypothermia, ECMO and early reperfusion (the CHEER trial). Resuscitation 2014.

32. Nichol G, Karmy-Jones R, Salerno C, Cantore L, Becker L. Systematic review of percutaneous cardiopulmonary bypass for cardiac arrest or cardiogenic shock states. Resuscitation 2006;70:381-94.

33. Blum JM, Lynch WR, Coopersmith CM. Clinical and billing review of extracorporeal membrane oxygenation. Chest 2015;147:1697-703

34. Cardarelli MG, Young AJ, Griffith B. Use of extracorporeal membrane oxygenation for adults in cardiac arrest (E-CPR): a meta-analysis of observationa studies. ASAIO J 2009;55:581-6.

35. Wallmuller C, Sterz F, Testori C, et al. Emergency cardio-pulmonary bypass in cardiac arrest: seventeen years of experience. Resuscitation 2013;84:326-30.

36. Riggs KR, Becker LB, Sugarman J. Ethics in the use of extracorporeal cardiopulmonary resuscitation in adults. Resuscitation 2015;91:73-5.

37. Lee S-W, Hong Y-S. Extracorporeal life-support in patients requiring CPR. The Lancet 2008;372:512-4.

38. Riou B, Beloucif S. Extracorporeal life support in out-of-hospital cardiac arrest: medical and ethical aspects, International Symposium. Presentation. European Society of Anaesthesiology (ESA); 2010. p. 6.

39. Raux M, Nicolas-Robin A, Riou B. L'arrêt cardiaque réfractaire: où en est-on? Urgences 2013: Société Française de Médecine d'Urgence; 2009. p. 1-14.

40. Czekajlo M. Worksheet for Evidence-Based Review of Science for Emergency Cardiac Care, Worksheet No. ALS-CPR\&A-002B.doc. International Liaison Committee on Resuscitation (ILCOR).9.

41. Sakamoto T. Worksheet for Evidence-Based Review of Science for Emergency Cardiac Care, Worksheet No. ALS-CPR\&A-002A.doc. International Liaison Committee on Resuscitation (ILCOR).

42. Link MS, Berkow LC, Kudenchuk PJ, et al. Part 7: Adult advanced cardiovascular life support: 2015 American heart association guidelines update for cardiopulmonary resuscitation and emergency cardiovascular care. Circulation 2015;132:S444-64, http://dx.doi.org/10.1161/CIR.0000000000000261.

43. Belohlavek J, Kucera K, Jarkovsky J, et al. Hyperinvasive approach to out-of hospital cardiac arrest using mechanical chest compression device, prehospital intraarrest cooling, extracorporeal life support and early invasive assessment compared to standard of care. A randomized parallel groups comparative study proposal. "Prague OHCA study". J Transl Med 2012;10:163.

44. Reynolds JC, Frisch A, Rittenberger JC, Callaway CW. Duration of resuscitation efforts and functional outcome after out-of-hospital cardiac arrest: when should we change to novel therapies? Circulation 2013;128:2488-94.

45. Ortega-Deballon I, De La Plaza-Horche E. A comprehensive approach to refractory cardiac arrest: saving more lives one way or another. Heart Lung Vesse 2014;6:149-51.

46. Avalli L, Mauri T, Citerio G, et al. New treatment bundles improve survival in out-of-hospital cardiac arrest patients: a historical comparison. Resuscitation 2014;85:1240-4

47. Yusuff HO, Zochios V, Vuylsteke A. Extracorporeal membrane oxygenation in acute massive pulmonary embolism: a systematic review. Perfusion 2015.

48. Perkins GD, Jacobs IG, Nadkarni VM, et al. Cardiac arrest and cardiopulmonary resuscitation outcome reports: update of the utstein resuscitation registry templates for out-of-hospital cardiac arrest: a statement for healthcare professionals from a task force of the International Liaison Committee on resuscitation (American Heart Association, European Resuscitation Council, Australian and New Zealand Council on Resuscitation, Heart and Stroke Foundation of Canada, InterAmerican Heart Foundation, Resuscitation Council of Southern Africa Resuscitation Council of Asia); and the American Heart Association Emergency Cardiovascular Care Committee and the Council on Cardiopulmonary, Critical Care, Perioperative and Resuscitation. Circulation 2015;132:1286-300, http://dx.doi.org/10.161/CIR.0000000000000144. 